\title{
Overcoming and Preventing Dental Implant Complications: Abutment Fracture Case Report
}

\author{
Se Hoon Kahm ${ }^{1}$, Chang-Hyun Kim², Sung-Joon $\mathrm{Kim}^{3}$ \\ ${ }^{1}$ Department of Dentistry, Jeju National University Hospital, Jeju, ${ }^{2}$ Department of Oral and Maxillofacial Surgery, \\ The Catholic University of Korea Seoul St. Mary's Hospital, Seoul, \\ ${ }^{3}$ Department of Dentistry, School of Medicine, Jeju National University, Jeju, Korea
}

\begin{abstract}
The introduction of osseointegrated dental implants in dentistry brought about a new era in everyday dental practice. For the past 50 years, prosthetic restoration with implant-supported prosthesis has developed into a viable and predictable treatment option. Alongside the increasing use of dental implants is the occurrence of many complications during implant placement (surgery), in the mechanical or prosthetic problem, and in the biological aspect. In particular, abutment or screw fracture as one of the mechanical complications can put the dentist in a tight spot in a clinical situation. It is hard to remove the fractured abutment and screw to restore it properly. Therefore, it is very important that clinicians consider possible complications in advance and make an appropriate treatment plan. We discuss cases of abutment fracture and mechanical/prosthetic complications together with the causes and solutions.
\end{abstract}

Key Words: Abutment fracture; Implant complication; Mechanical complication; Prosthetic complication

\section{Introduction}

Since its introduction in northern Europe in the 1960s, dental implant has been used all over the world as an option to restore teeth and periodontal tissues ${ }^{1)}$. In the early stage, dental implant prosthesis was used restrictively to replace removable prosthesis; currently, however, it is also used for stationary prosthesis. This treatment utilizes various methods including osseointegration after 3 6 months of treatment without loading to connect prosthesis or immediate loading ${ }^{2}$.

Though the popular use of this treatment has provided many advantages to patients and clinicians, dental implant also gives rise to many complications. In the early stage, there were many surgical complications due to poor osseous tissue as well as mechanical/prosthetic complications such as fracture and loosening of screw caused by the complicated implant structure of Brånemark et al. ${ }^{1)}$.

Corresponding Author: Sung-Joon Kim

Department of Dentistry, School of Medicine, Jeju National University, 102 Jejudaehak-ro, Jeju 690-756, Korea TEL : +82-64-717-1843, FAX : +82-64-717-1846, E-mail : samuelsj@jejunu.ac.kr

Received for publication May 20, 2013; Returned after revision May 30, 2013; Accepted for publication June 7, 2013

Copyright $\odot 2013$ by Korean Academy of Dental Science

(c) This is an open access article distributed under the terms of the Creative Commons Attribution Non-Commercial License (http://creativecommons.org/licenses/ by-nc/3.0) which permits unrestricted non-commercial use, distribution, and reproduction in any medium, provided the original work is properly cited. 
In surgery in those days, severe side effects such as damage to inferior alveolar nerve or mandibular canal were generated because it was hard to diagnose the insufficiency of quality and amount of bone. Moreover, there were many mechanical/ prosthetic problems caused by complicated prosthetic structure and poor mechanical design of denture to fix the implant for edentulous jaw ${ }^{3)}$.

Over time, the success rate of implant increased drastically thanks to the paradigm shift in implant treatment, improvement of design, and surface treatment of dental implant and accurate diagnosis and surgery ${ }^{4,5}$. Note, however, that long-term use of implants also caused new problems such as biological complications including periimplantitis, for which a definite treatment approach has not been found yet, and a need for extra care for patients with periodontitis ${ }^{6}$.

In particular, many mechanical complications that may be generated during long- or short-term observations of implant patients including fracture of screw or abutment can embarrass dentists without enough experience. Despite the advanced implant design and mechanical improvement, the problems such as loosening and fracture of abutment screw, abutment fracture, and prosthesis fracture caused by various conditions including unexpected lateral pressure still remain without

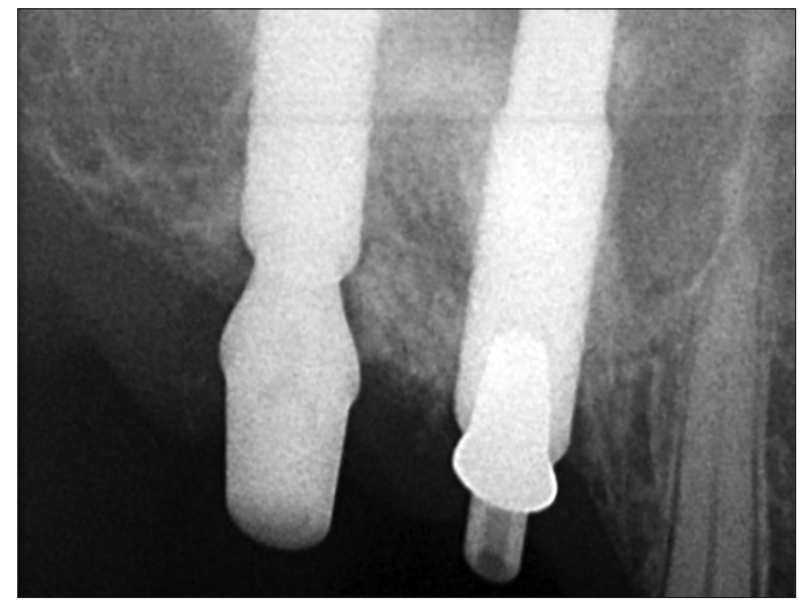

Fig. 1. Radiograph of root apex after removing prosthesis. clear solutions. In this paper, we review cases of complications based on abutment fracture one of the mechanical complications to find out its causes, problems, solutions, and methods of prevention.

\section{Case Report}

\section{Case 1}

The Case 1 is in relation to implant screw-andcement prosthesis prosthesis of a 50-year-old male patient who had a D (diameter) $5.0 \mathrm{~mm} \times \mathrm{H}$ (height) $13.0 \mathrm{~mm}$ internal connection-type implant placed for restoration. The patient visited the hospital complaining of food impaction around the existing prosthesis and mobility of prosthesis. He received prosthetic restoration of implant in the \#16, 17 posterior teeth manufactured 5 years ago; \#16 used a non-hex-type screw-retained-type prosthesis, and \#17 used a non-hex-type cement-retained-type prosthesis. The patient had not visited the hospital for 2 years and visited 1 week ago due to the inconvenience of prosthesis.

Mobility of prosthesis was detected, and the abutment screw in the screw retaining area was removed using torque wrench to remove the prosthesis accordingly. But there was a defect in the structure of the upper prosthesis as shown in Fig. 1, a radiograph of the root apex, and Figs. 2 and 3,

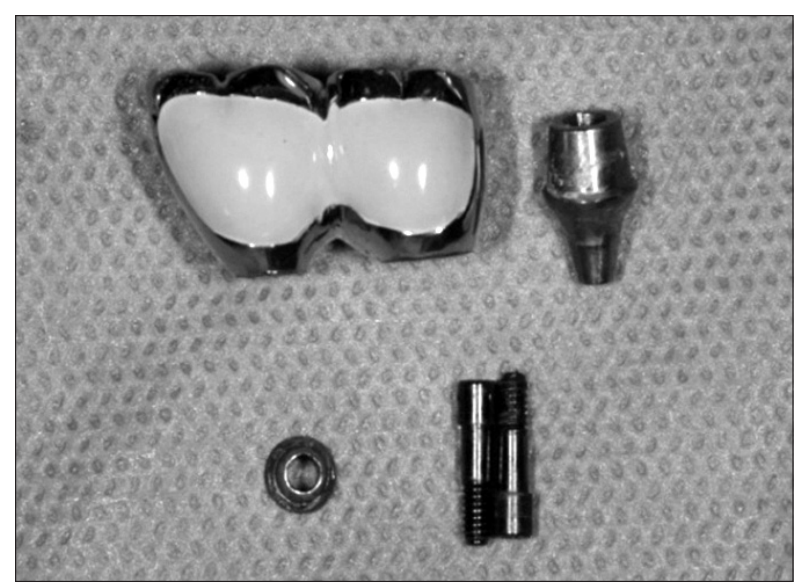

Fig. 2. Removed prosthesis and fractured abutment. 
pictures of the removed prosthesis and fractured abutment. Antagonistic teeth used an implantretained-type prosthesis.

This case was likely to be associated with abutment facture because prosthesis received loads including lateral pressure for a long time after loss of cement from the cement-retained-type prosthesis. In particular, if antagonistic teeth are in the implant group, complications can arise unless chewing pressure especially lateral pressure is controlled properly. In addition, the posterior screw-retained-type abutment will have excessive loading if dissolution and failure of cement in the posterior abutment are not managed properly with regular inspection. In addition, error in prosthetic process and defect of abutment may be influencing factors. Considering the location of fracture in Fig. 2, there may be a need to consider the problem in the joint area between the custom cast abutment with screw retention (UCLA) abutment and the upper structure when casting.

The separated lower structure of the UCLA abutment was removed including the posterior cement-retained-type abutment, and prosthesis was manufactured again by collecting impression implant from fastener level. The posterior abutment was changed to the hex type, and conformity of the prosthesis was checked thoroughly to connect 'passive fit' prosthesis that does not deliver excessive loading to the abutment.

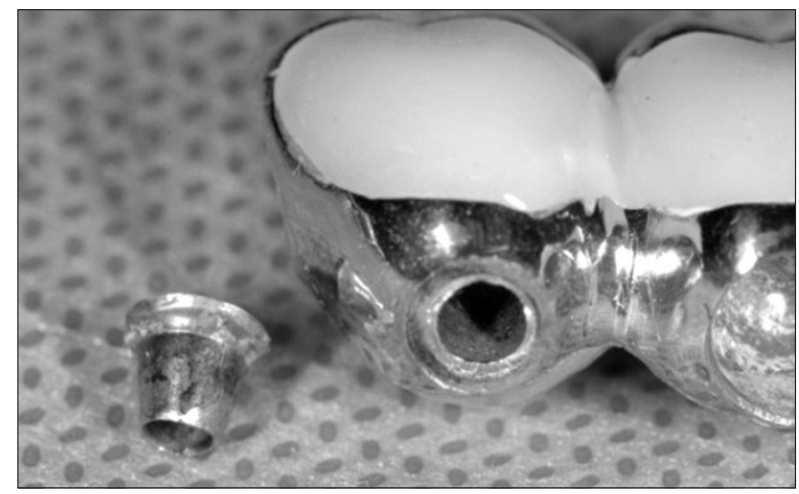

Fig. 3. Fractured abutment and lower part of prosthesis.

\section{Case 2}

The Case 2 is related to implant cement-retainedtype prosthesis of a 48 -year-old male patient who had 2 D5.0 $\mathrm{mm} \times \mathrm{H} 10.0 \mathrm{~mm}$ internal connection-type implants placed for restoration. The patient visited the hospital complaining of mobility of prosthesis that occurred a few months ago in the right lower molar area. He was using 2 cement-retained-type prostheses using cement-retained-type abutment manufactured 4 years ago, and he visited the hospital due to the continuous mobility of the prosthesis without being examined for 3 years. For antagonistic teeth, removable partial denture was used, but it was manufactured to restore the lost molar in the left molar area. The antagonistic teeth of \#46, 47 teeth were the \#16, 17 removable partial

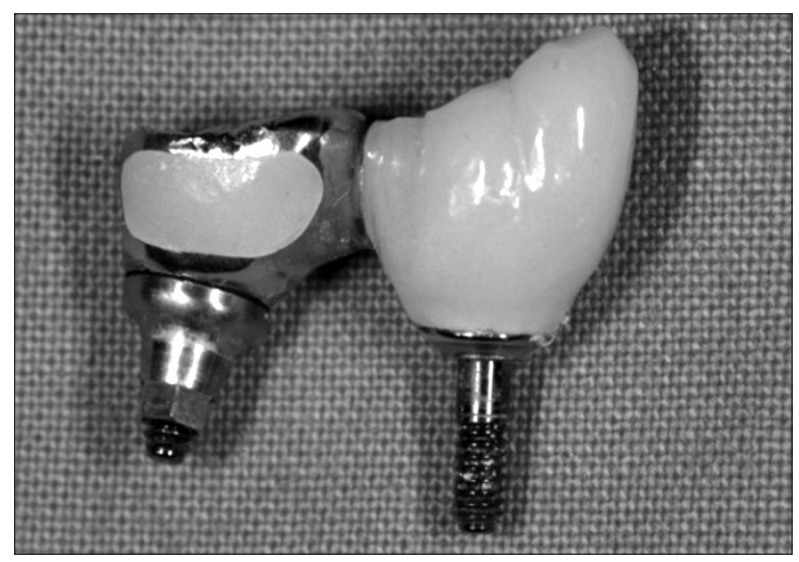

Fig. 4. Removed prosthesis and abutment.

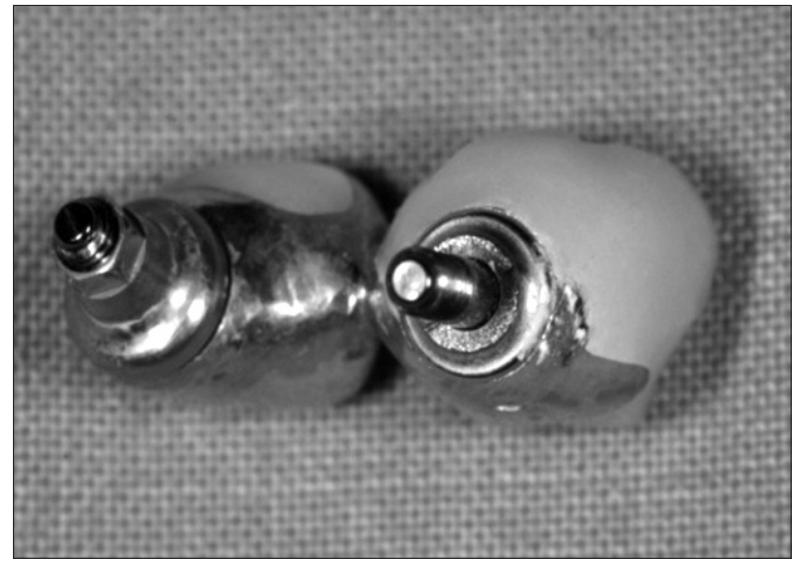

Fig. 5. Removed prosthesis and lower part of abutment. 
denture abutments restored with crown, forming a major chewing part.

One or more of the 2 abutments were expected to have attachment failure or loosening of screw including loss of cement, thus the screw was removed by creating a hole at the top of the prosthesis. After removing it, fractured abutment was identified in the prosthesis and the lower part of the remaining abutment as shown in Figs. 4, 5, and 6.

To remove the abutment remaining in the implant, the 'removal kit' delivered from each implant manufacturer was used, and prosthesis was manufactured again by collecting impression at the fastener level. In this case, 2 implants placed in different directions were of the cement-retained type, and at the time of manufacture, stress may be concentrated when applying to the front abutment, or there may be excessive lateral pressure around the \#46 tooth. Even when using custom abutment or angled abutment, goodness of fit or retention force of the upper structure may decrease compared to that of a correctly placed implant, and misfit within the prosthesis may be undetected due to cement. If a misfit is generated when manufacturing prosthesis, such may be a major cause of fracture, and great care is needed if antagonistic teeth are natural teeth of implant fixed-type prosthesis. When manufacturing prosthesis again, the height and angle of the \#46 MB cusp tip were lowered, and goodness of fit of prosthesis was evaluated to

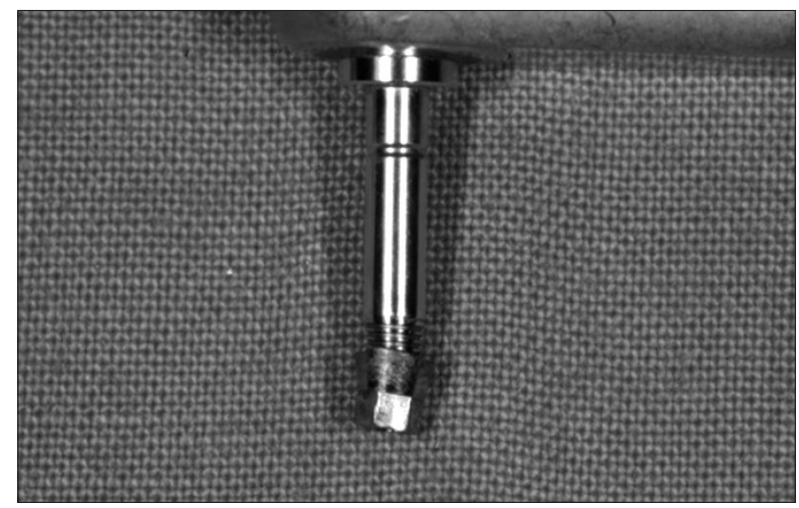

Fig. 6. Removal of fractured abutment using an exclusive tool. restore with cement-retained-type prosthesis that delivers 'passive fit.'

\section{Case 3}

This case is in relation to a restoration using a single implant for a 45-years-old male patient's left maxillary central incisor. With D4.0 mm $\times H 11.5 \mathrm{~mm}$ internal connection-type implant, screw connectiontype restoration with manually manufactured ceramic was used on the upper part of the zirconia abutment. Fracture occurred 15 months after the prosthesis was placed. The patient had regular examinations after 3 months, 6 months, and 1 year and visited the hospital due to deciduous prosthesis identified at the examination after 1 year.

When manufacturing prosthesis, first, for the aesthetic restoration of prosthesis, cement was placed at the top of abutment using zirconia abutment provided by the manufacturer. However, fracture occurred at the abutment in the lower part of the prosthesis. As shown in Figs. 7 and 8, the location of the fracture is $1 / 3$ from the center of abutment. In this case, implantation was done by placing ceramic on the non-hex-type zirconia abutment; therefore, internal flaw caused by the repeated placement of ceramic and heat treatment

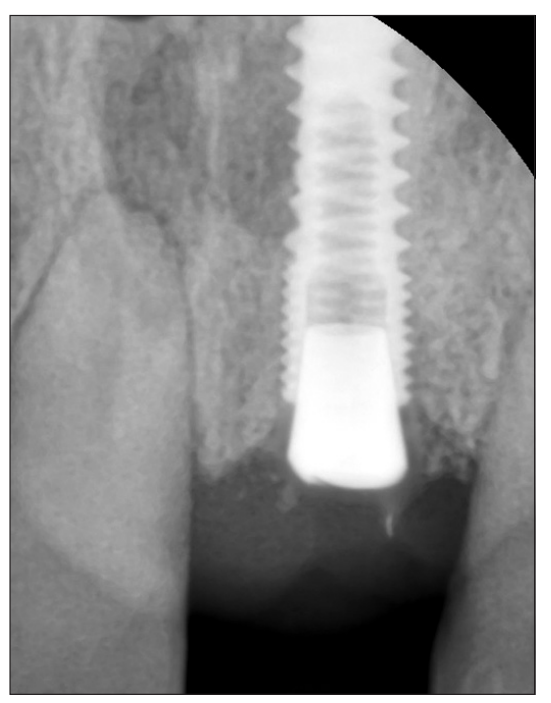

Fig. 7. Radiograph of root apex of fractured ceramic abutment. 


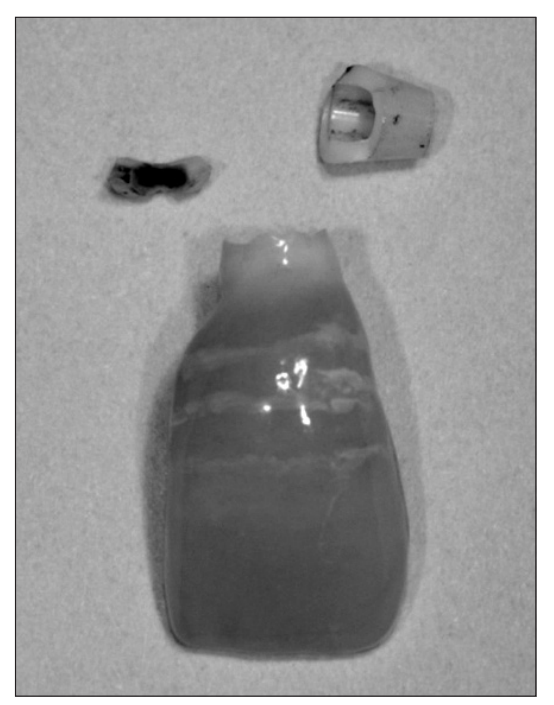

Fig. 8. Upper structure of ceramic abutment and lower part of fractured abutment.

was likely to spread due to repeated loading caused by excessive occlusion force or disadvantageous delivery of loading in the anterior area. However, there was no specific problem in the regular occlusion test and adjustment. In addition, there may have been a flaw in the abutment, or loading is concentrated on a certain location due to the uneven contact surface between the exterior of the abutment and inside of the implant fastener. For restoration, impression was collected again from the implant fastener level, and cement-retainedtype prosthesis was manufactured using normal titanium abutment.

\section{Discussion}

\section{Mechanical/Prosthetic Complications of Im-} plant and Their Causes

Complications of implant can be classified as surgical complications, mechanical/prosthetic complications, and biological complications. Surgical complications can be divided into intraoperative complications and postoperative complications. Intraoperative complications include bleeding, neurological damage, maxillofacial fracture, perforation in the maxillary sinus or nostril, dehiscence, bone boring, and damage of adjacent tooth. Postoperative complications include infection, bleeding, hematoma, chronic inflammation of the maxillary sinus, and lesion around the implant ${ }^{7}$.

Mechanical/prosthetic complications include loosening and fracture of screw, fracture of abutment, remnant/loss of cement, fracture of prosthesis and porcelain, and, in some cases, fracture of implant ${ }^{8)}$. According to Berglundh et al. ${ }^{9}$, the average fracture rate of implant in retained-type prosthesis was $0.74 \%$; the complication rate of the internal connection-type structure was $0.23 \%$, and that of the upper structure was $0.24 \%$. For restoration of a single tooth, the complication rate slightly decreased-the average fracture rate of implant was $0 \%$, the complication rate of the internal connection-type structure was $0.30 \%$, and that of the upper structure was $0.16 \%$. The most common biological complication is periimplantitis, followed by abnormal bone loss, inflammation of the gums, periodontal abscess, and loss of implant ${ }^{10)}$. According to Brägger et al. ${ }^{11)}$, though biological complications occur more frequently than mechanical complications, they showed higher failure rate of the implant itself; hence the need to try harder to prevent and manage complications.

The aforesaid complications result from many reasons. With respect to the operator, improper treatment plan or error in design and manufacture of prosthesis may cause complications. If a specific implant or structure has excessive loadings due to improper plan or design of prosthesis or disadvantageous dynamic structure caused by long cantilever, mechanical complications may occur. Likewise, with respect to the patient, bad oral habits that can cause excessive occlusion force such as teeth grinding and clenching and occlusion form of implant and natural antagonistic teeth and excessive loading around the implant may cause complications. Finally, in terms of implant/ prosthesis, poor quality of implant product, 
disadvantageous dynamic structure or design of implant, small implant considering occlusion force or its location, error in placement, or improper prosthesis may cause problems by generating excessive loading in the abutment or upper structure $^{12,13)}$

Though there was misfit between parts attri-butable to errors of implant manufacturers such as problems in implant, implant abutment, and abutment screw, instances of such have been reduced drastically with the standardization of the manufacturing process and reinforcement of quality control (QC) by domestic implant manufacturers. Moreover, in terms of problems in the placement process, fracture can be prevented by observing the principles, and QC of clinic must be controlled properly. In fact, if we exclude problems in the implant itself or placement, complications may be prevented because the operator can provide accurate analysis and proper treatment plan by controlling factors on the patient and implant/ prosthesis sides. Therefore, the operator is believed to be the most important factor.

\section{Prevention and Solution of Mechanical/Pro-} sthetic Complications of Implant

Many unexpected problems can arise in a clinical situation, including mechanical/prosthetic complications of implant. Normal fracture of prosthesis or ceramic can be solved easily if prosthesis can be easily removed. If repair is needed, the problem of contact surface material can be addressed by providing proper prosthesis form for the patient or adjusting the width, part, or strength of the occlusal contact surface. In addition, wearing of occlusion support device (occlusal guard, night guard) to adjust the nonfunctional occlusion force helps prevent mechanical complications ${ }^{14)}$.

Loosening and fracture of screw can be minimized by manufacturing accurate prosthesis to disperse loading on the abutment and abutment screw, and selecting proper full load, material, and type of abutment and screw is critical ${ }^{15,16)}$. In addi- tion, regular examination can prevent many complications, which may be detected after the fracture of abutment or prosthesis screw with relying on the feeling of patient alone. In the early stage after manufacturing the prosthesis, prosthesis and occlusion should be inspected carefully and frequently. Even after a certain period, regular examination and radiography can help prevent possible complications ${ }^{17,18)}$.

If fractured screw or abutment is detected, the use of supporting devices such as 'removal kit' or experience of removing prosthesis will help the most. Fractured screw or abutment can be removed easily using a proper device, and the operator's experience in using various tools or methods (i.e. reverse rotation by explorer or ultrasonic device etc.) before commercialization of such device can be the first step to resolve the mechanical complication.

After removal, a fractured abutment screw is generally replaced, or the prosthesis is manufactured again.

Before performing the normal re-manufacture of prosthesis, one should ask, "Why did such complication occur?" Intraoral occlusion test will be good; sometimes, however, there is a need to conduct overall occlusion analysis to collect impression. Of course, if prosthesis needs to be manufactured again, impression should be taken to provide proper occlusion. In addition, it is sometimes necessary to replace with a more appropriate type of abutment for loading considering the properties of abutment or to change the cement-retained type to screw-retained type and vice versa. Proper material for prosthesis and abutment should also be selected. If the complication is associated with intraoral bad habit, various physical therapies and occlusion protector will be necessary.

Implant placement may give rise to various complications. Among these complications, mechanical/prosthetic complications can be prevented with accurate analysis and treatment plan, ma- 
nufacture of accurate prosthesis, and regular examination. If a complication occurs, there is a need to detect it promptly, identify its cause, and react to it to avoid the re-manufacture of implant prosthesis or loss of implant and for proper treatment.

Resolving and presenting implant complications start with going back to the basics and will be able to be achieved through accurate diagnosis and treatment plan; selection of proper design, form, and material of prosthesis; and manufacture of accurate prosthesis.

\section{References}

1. Brånemark PI, Adell R, Breine U, Hansson BO, Lindström J, Ohlsson A. Intra-osseous anchorage of dental prostheses. I. Experimental studies. Scand J Plast Reconstr Surg. 1969; 3: 81-100.

2. Albrektsson T, Zarb G, Worthington P, Eriksson AR. The long-term efficacy of currently used dental implants: a review and proposed criteria of success. Int J Oral Maxillofac Implants. 1986; 1: 11-25.

3. Hong SH. Problems and complications of dental implant prosthesis. J Korean Dental Assoc. 2002; 403: 948-51.

4. Tarnow DP, Emtiaz S, Classi A. Immediate loading of threaded implants at stage 1 surgery in edentulous arches: ten consecutive case reports with 1- to 5-year data. Int J Oral Maxillofac Implants. 1997; 12: 319-24.

5. Degidi M, Piattelli A. 7-year follow-up of 93 immediately loaded titanium dental implants. J Oral Implantol. 2005; 31: 25-31.

6. Zitzmann NU, Berglundh T. Definition and prevalence of peri-implant diseases. J Clin Periodontol. 2008; 35(8 Suppl): 286-91.

7. Lee HJ, Yeo DS, Lim SY, An KM, Sohn DS. Complications associated with dental implant surgery; case report. J Korean Oral Maxillofac Surg. 2007; 33: 173-80.
8. Schwarz MS. Mechanical complications of dental implants. Clin Oral Implants Res. 2000; 11 Suppl 1: 156-8.

9. Berglundh T, Persson L, Klinge B. A systematic review of the incidence of biological and technical complications in implant dentistry reported in prospective longitudinal studies of at least 5 years. J Clin Periodontol. 2002; 29 Suppl 3: 197-212.

10. Lang NP, Wilson TG, Corbet EF. Biological complications with dental implants: their prevention, diagnosis and treatment. Clin Oral Implants Res. 2000; 11 Suppl 1: 146-55.

11. Brägger U, Karoussis I, Persson R, Pjetursson B, Salvi G, Lang N. Technical and biological complications/failures with single crowns and fixed partial dentures on implants: a 10-year prospective cohort study. Clin Oral Implants Res. 2005; 16: 326-34.

12. Taylor TD. Prosthodontic problems and limitations associated with osseointegration. J Prosthet Dent. 1998; 79: 74-8.

13. Goodacre CJ, Bernal G, Rungcharassaeng K, Kan JY. Clinical complications with implants and implant prostheses. J Prosthet Dent. 2003; 90: 121-32.

14. Morgan MJ, James DF, Pilliar RM. Fractures of the fixture component of an osseointegrated implant. Int J Oral Maxillofac Implants. 1993; 8: 409-14.

15. Byrne D, Jacobs S, O'Connell B, Houston F, Claffey N. Preloads generated with repeated tightening in three types of screws used in dental implant assemblies. J Prosthodont. 2006; 15: 164-71.

16. Jaarda MJ, Razzoog ME, Gratton DG. Effect of preload torque on the ultimate tensile strength of implant prosthetic retaining screws. Implant Dent. 1994; 3: 17-21.

17. Park SH, Wang HL. Implant reversible complications: classification and treatments. Implant Dent. 2005; 14: 211-20.

18. Mericske-Stern R. Prosthetic considerations. Australian Dent J. 2008; 53: S49-S59. 